\title{
Monitoring HbA1C in patients on continuous subcutaneous insulin infusion for the treatment of Type 1 Diabetes
}

P De Silva, G Kayello, O Oso

\section{Introduction and Method}

- A retrospective study of 33 paediatric patients with type 1 diabetes mellitus on insulin pump therapy

- Compared the HbA1C levels before and after starting insulin pump therapy

- Compared the change in HbA1C levels between males and females and in different age groups

\section{Results}

Age at diagnosis

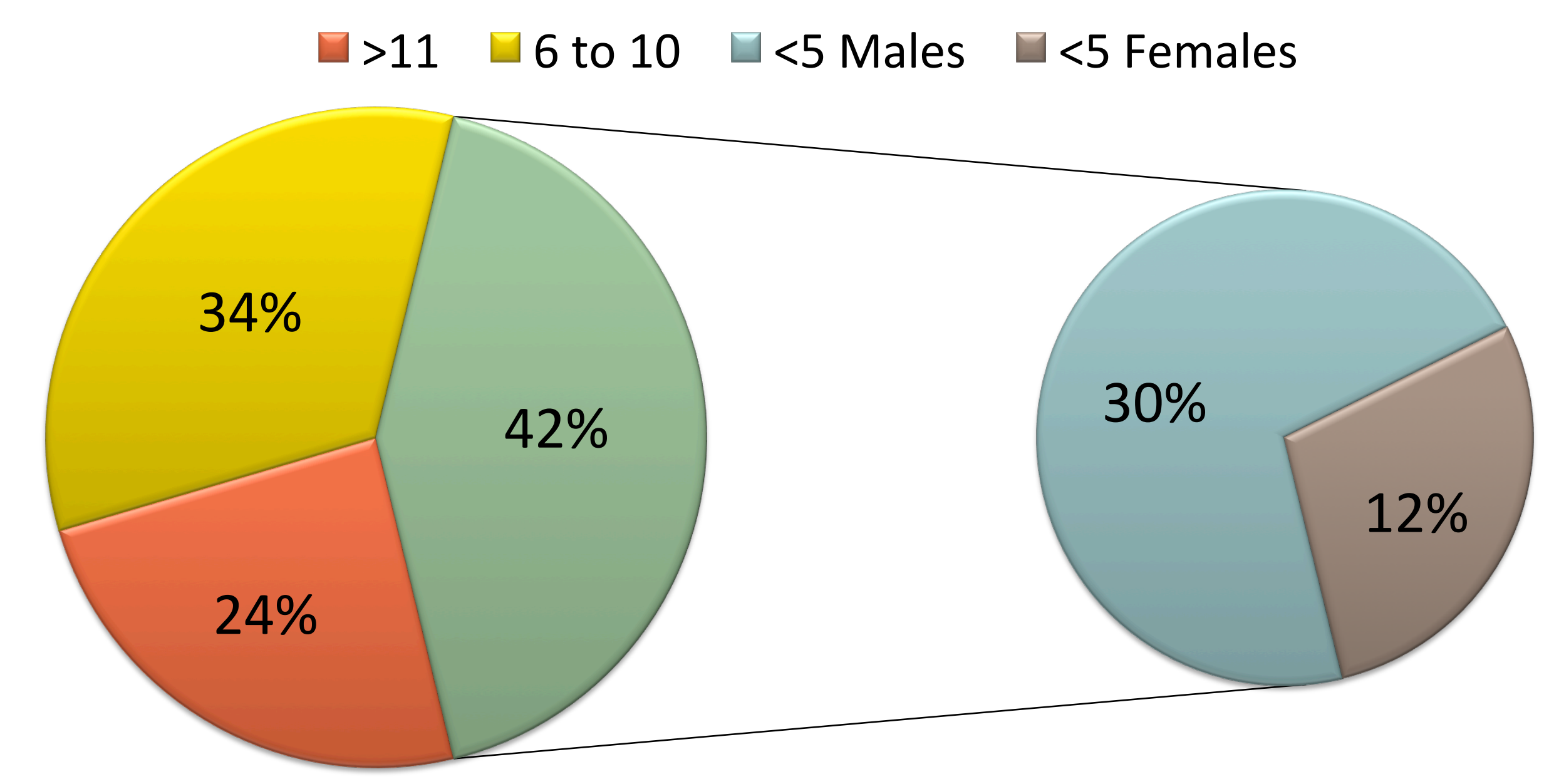

Gender distribution

$\square$ Females $\square$ Males
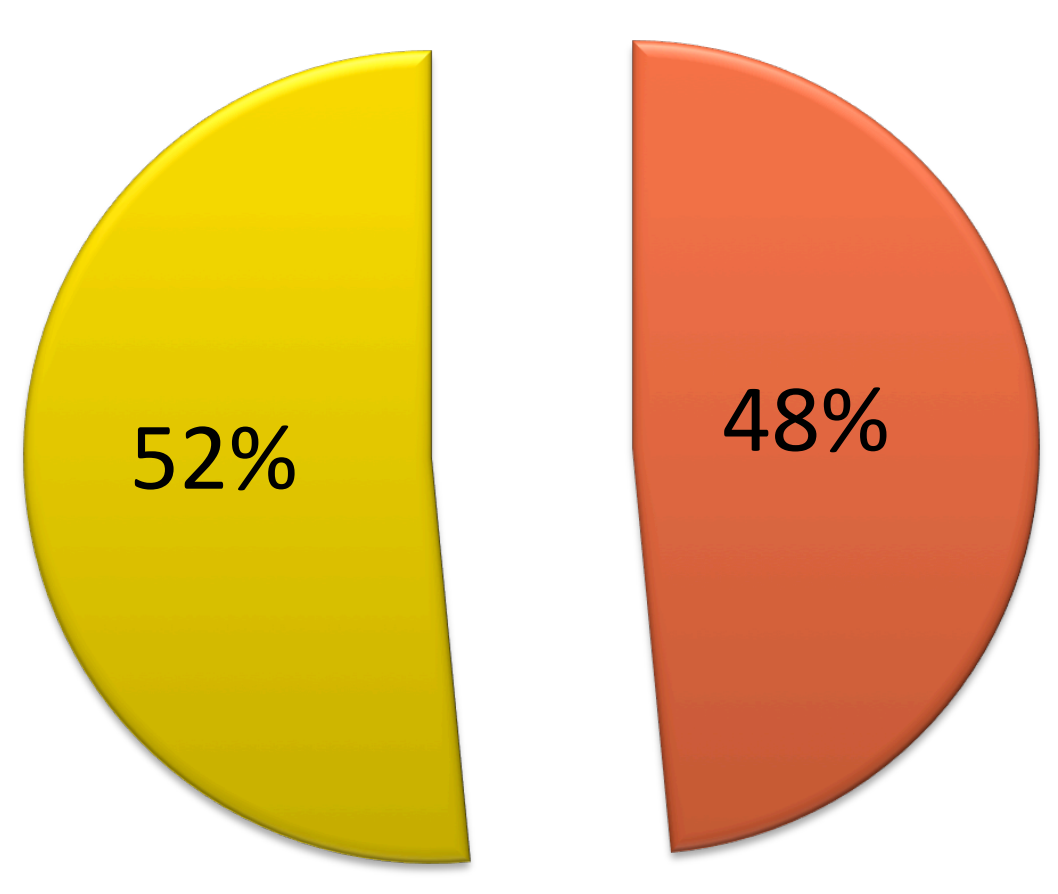

Age of starting the pump

$\square<10 \square 11$ to $13 \square>14$

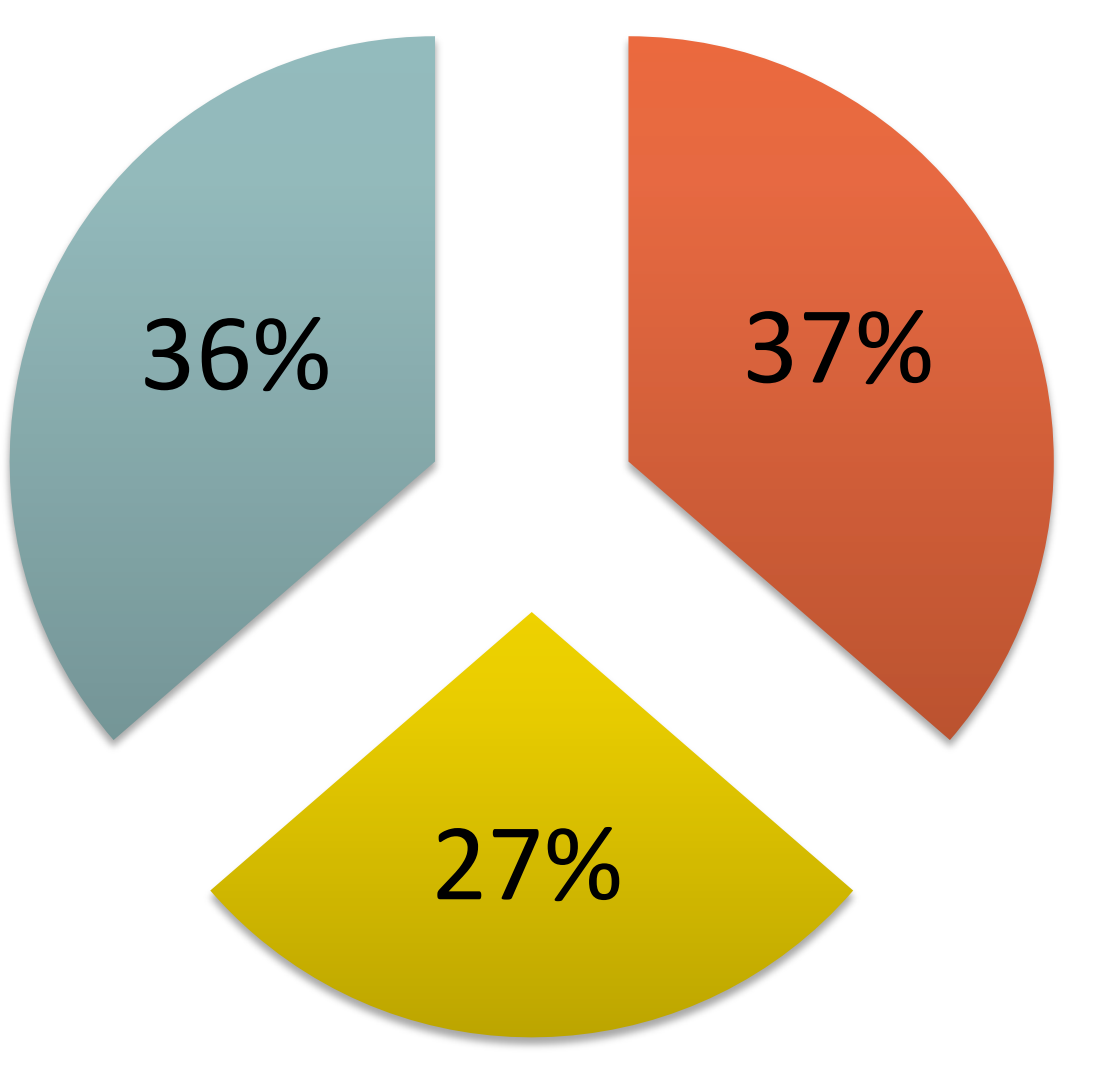

Mean $\mathrm{HbA1c}$ before and after starting insulin pump therapy

$\square$ Improved by $>0.5 \% \quad \square$ No improvement $\square$ Worsened by $>0.5 \%$

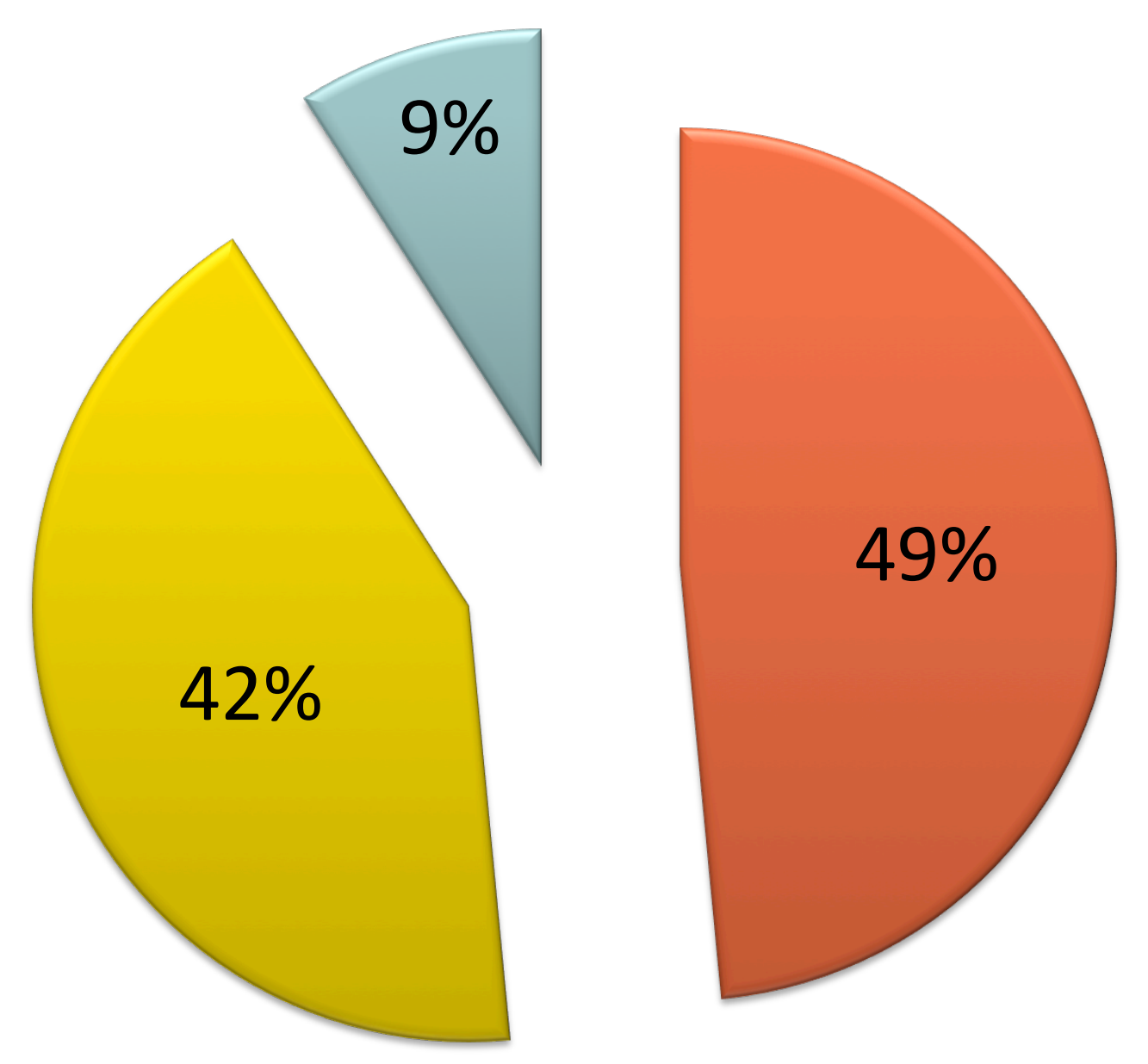

- The age of diagnosis was $<5$ years in the majority ( $42 \%)$

- The gender distribution was almost equal

- The majority of patients were $>11$ years when insulin pump therapy was initiated (63\%).

- There was an improvement of $\mathrm{HbA} 1 \mathrm{C}$ of greater than $0.5 \%$ in $49 \%$ of our patient group

- $42 \%$ of patients did not improve their HbA1c levels

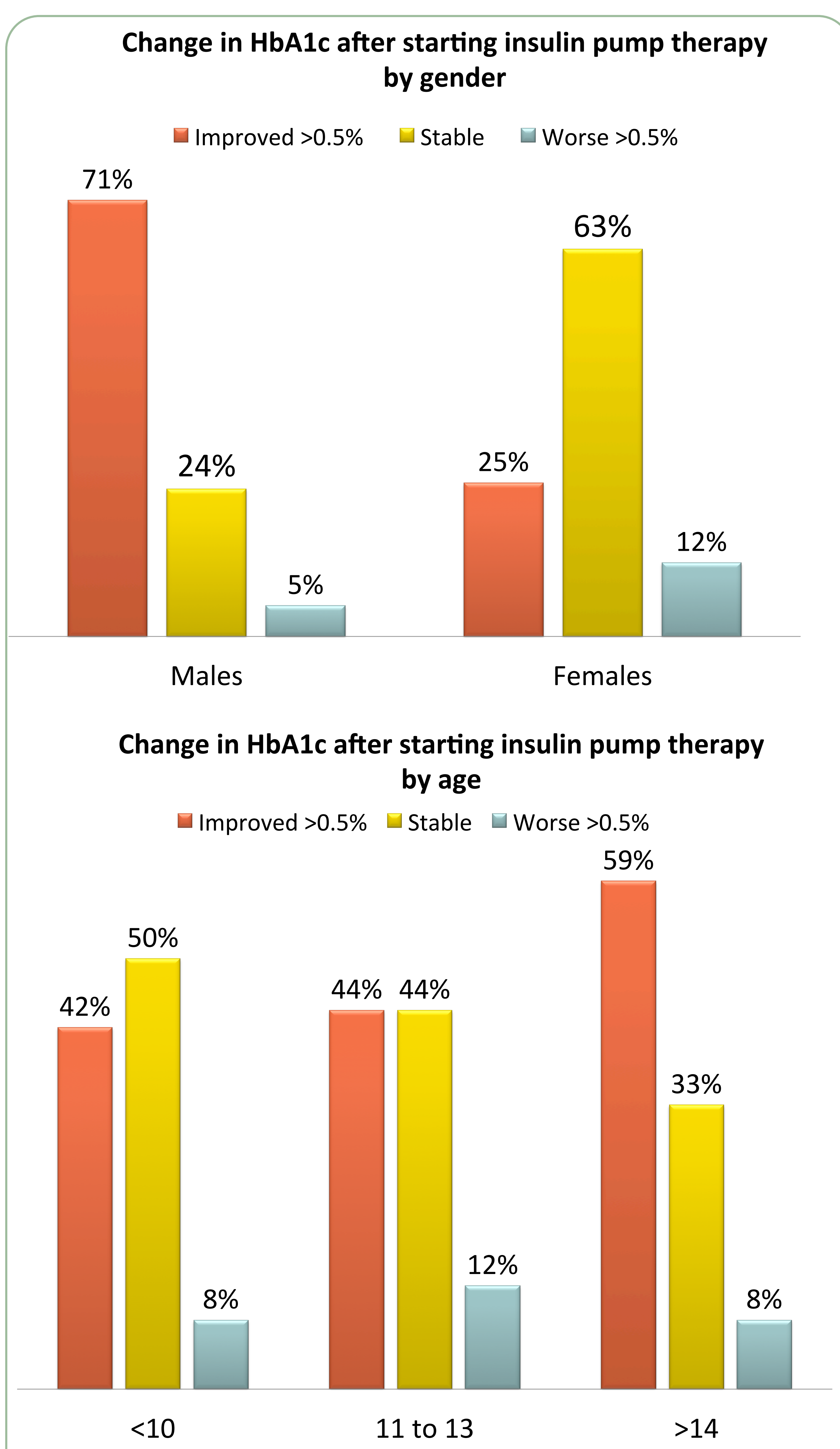

- $71 \%$ of male patients showed an improvement of their HbA1c compared to $25 \%$ of female patients

- > 14 year olds improved their HbA1c results more compared to younger age groups

\section{Conclusions}

- The benefit of subcutaneous insulin pump therapy varied between male and female patients and among different age groups

- Several factors need to be addressed in the future to achieve an improvement in $\mathrm{HbA} 1 \mathrm{C}$ e.g. compliance, dietary advice, training and education 